\title{
AS IMAGENS DO EU E DO OUTRO (ESTRANGEIRO) EM ASTERIX ${ }^{1}$
}

\section{IMAGES OF ME AND THE OTHER (FOREIGNER) IN ASTERIX}

\section{LAS IMÁGENES DEL YO Y DEL OTRO (EXTRANJERO) EN ASTÉRIX}

\author{
Silvia Ines Coneglian Carrilho de Vasconcelos ${ }^{1}$ \\ 1.Professora Doutora do Departamento de Língua e Literatura Vernáculas e do PROFLETRAS da Universidade Federal de Santa Catarina. E-mail: \\ silviaconeglian@terra.com.br.
}

\begin{abstract}
Resumo: Asterix, a personagem central da famosa História em Quadrinhos francesa de Goscinny e Uderzo, juntamente com as personagens Obelix, Paronamix, Idéiafix, entre outros, podem ser considerados como representantes de uma "francesidade" discursivo-identitária. Dos enunciados verbais e das representações imagéticas da história em quadrinhos é possível evidenciar relações de poder e projeção de imagens de gauleses (o eu) e, por extensão, os franceses, bem como de romanos e, por extensão, qualquer não-francês (o outro, o estrangeiro). Nosso objetivo neste texto é apresentar uma análise discursiva, na perspectiva da Análise do Discurso francesa, das representações imaginárias do eu e do outro na referida HQ. A partir da análise empreendida é possível indicar a positivação da imagem do(s) EU(s), como os gauleses (leia-se os franceses) e a negativação da imagem do(s) OUTRO(s), como os romanos (leia-se o estrangeiro).
\end{abstract}

Palavras-chave: Análise do Discurso, História em quadrinhos, Mídia, Imagem, Estrangeiridade.

\begin{abstract}
Asterix, the main hero in the well-known French cartoon by Goscinny and Uderzo, together with Obelix, Paronamix, Ideiafix and the other protagonists, may be considered the representatives of discursive-identitarian French-ness. Power relationships and projections of Gaulist images ('me') and, by extension, the French, may be perceived through verbal enunciations and image representations of this specific cartoon; likewise, the Romans and, by extension, the non-French (the other, the foreigner). Based on French Discourse Analysis, current paper analyzes the imaginary representations of the 'me' and the 'other' in the Asterix cartoon. The positiveness of the image of the ME, as the Gauls (or French), and the negativeness of the image of the OTHER, as the Romans (or foreigners) are underscored.
\end{abstract}

Keywords: Discourse analysis, Cartoons, Social Media, Images, Foreignness.
Resumen: Astérix, el personaje central de la exitosa Historieta francesa de Goscinny y Uderzo, junto a los personajes Obélix, Paronamix, Ideiafix, entre otros, pueden ser considerados como representantes de una "francesidad" discursivo-identitaria. De los enunciados verbales y de las representaciones imaginarias de la historieta es posible evidenciar relaciones de poder y proyección de imágenes de galeses (el yo) y, por extensión, los franceses, bien como de romanos y, por extensión, cualquier no-francés (el otro, el extranjero). Nuestro objetivo en este texto es presentar un análisis discursivo, en la perspectiva del Análisis del Discurso de matriz francesa, de las representaciones imaginarias del yo y del otro en la referida Historieta. A partir del análisis emprendido es posible señalar la positivación de la imagen del (de los) yo(s), como los galeses (léase los franceses) y la negativización de la imagen del (de los) OTRO(s), como los romanos (léase el extranjero).

Palabras-clave: Análisis del Discurso, Historieta, Medios de Comunicación, Imagen, Extranjeridad.

Recebido em: 22/01/2021

Aprovado em: 10/04/2021

${ }^{1}$ Este artigo é uma retomada ampliada de uma comunicação apresentada na VIIIle. Journée d'études françaises (UEM, 2002), sob o título "Les images du je et de l'autre (étranger) dans Astérix. 


\section{Introdução}

As histórias em quadrinhos apresentam uma característica singular que é a de reunir duas riquíssimas formas de expressão cultural: a literatura e as artes plásticas. Isso as torna um objeto de leitura particularmente sedutor tanto para crianças quanto para adultos. Elas já foram alvo de críticas tanto dentro quanto fora da escola, mas hoje gozam de certo prestígio, sendo adotados por escolas como mais um recurso didático no processo de leiturização. Por se constituir um fenômeno midiático, as histórias em quadrinhos têm também um estatuto pedagógico, já que veicula e inculca valores, atitudes, crenças, e constitui identidades. Como qualquer outro discurso de mídia, as HQ permitem a um analista depreender, entre muitos indicadores, os de subjetivação. Neste artigo objetivamos apresentar as representações imaginárias* presentes em HQ de Asterix, o Gaulês, de Goscinny e Uderzo (1986 e 1987), especificamente quanto às posições de eu e de outro ${ }^{2}$, como forma de evidenciar o funcionamento discursivo que constrói uma imagem de estrangeiridade e de francesidade.

Para tanto, tomamos como base teórica alguns pontos da Análise de Discurso de linha francesa (Pêcheux, Foucault), estudos sobre estrangeiridade (Viñar, Todorov), sobre os quais passaremos a discorrer no próximo item.

As HQ tomadas como exemplo de ilustração das categorias de análise que aqui nos interessou demonstrar são: A Cizânia (1986, original francês La Zizanie,1986); Asterix e A Surpresa de César (1987, original francês Asterix et La Surprise de Cesar, 1985), ambas traduzidas por Cláudio Varga, editadas pela Editora Record (Rio de Janeiro) e impressas na Itália (Milão). As duas HQ são histórias longas, impressas em cores, em papel de alta qualidade.

\section{O olhar teórico: AD, alteridade e estrangeiridade}

A perspectiva teórica que aqui adotamos nos leva a considerar a linguagem como um trabalho, como uma forma de interação entre humanos e o mundo que os cerca. Desse modo o texto - escrito ou oral - é construído e apreendido no processo de interlocução e sua significação se dá no espaço discursivo constituído pelos interlocutores, que ocupam posições discursivas, determinadas socio-historicamente. Ao dizer, cada locutor o faz dentro de uma sociedade discursiva (FOUCAULT, 1999) a partir de uma imagem de si (A), do outro (B) e do referente (R) (PÊCHEUX, 1969/1983). Essas imagens se cruzam no jogo discursivo, propiciando ao analista perceber as representações feitas pelos interlocutores.

Assim, quando A diz algo (R) a B, A tem uma imagem de si, uma imagem de B, uma imagem de R, bem como tem uma imagem da imagem que B deve ter dele (IB) e uma imagem da imagem que B tem de A. Em relação a B, o mesmo ocorre. Quando B diz algo a A, B tem uma imagem de si, uma imagem de A, uma imagem de R, bem como tem uma imagem da imagem que A deve ter dele (IA) e uma imagem da imagem que A deve ter de B (PÊCHEUX, 1993, p. 83-84). Esse jogo discursivo proporciona antecipações do dizer, recuos, já que cada locutor projeta imagens de si, do outro e do referente a cada lance. As imagens evidenciáveis nos discursos, antes de estarem já dadas a priori, são constituidoras dos sujeitos que ocupam posições e, ao discursarem, se confrontam com o outro cujo discurso também lhe é constituidor.

\footnotetext{
* Não podemos deixar de registrar que, embora estejamos apoiadas em um conjunto teórico produzido com mais ênfase em solo francês, nosso olhar é de uma leitora que constrói seu dizer a partir de um solo latinoamericano, brasileiro.

${ }^{2}$ Não desconhecemos as considerações do campo da Antropologia acerca da problematização dos conceitos de eu e de outro. Esta dicotomização não é universalmente compartilhada pelas populações humanas, mas uma dualidade que é parte da lógica eurocentrada de concepção de identidades. Mafeje (1991, 2000), entre outros, há muito se dedicaram a pensar a lógica alterizada como base do pensamento colonialista e ocidental. No entanto, a marcação das posições de eu e do outro nas HQ (da década de 1980) analisadas parecem apontar para uma distinção mais fechada, com fronteiras bem delineadas. E essa dicotomia é a que aqui nos interessa.
} 
Assim, todo dizer é heterogêneo e nunca é neutro (AUTHIER-REVUZ, 1990, p. 72), e nele as imagens do eu, do outro e do referente se projetam.

\section{Alteridade}

Como nos ensina Claude Lévi-Strauss (1973), em todo contato entre duas civilizações, há choques, embates, preconceitos. Viñar (1998), referindo-se aos estudos de antropologia política de Pierre Clastres (de 1972 e de 1974), comenta um fato bastante comum entre os membros de algumas aldeias indígenas sul-americanas: a designação de si mesmos por "os homens", mas "reservavam para seus congêneres de tribos vizinhas termos como "ovo de piolho", "subhomens" ou equivalentes com valor pejorativo" (p. 173). Esse etnocentrismo (eloquente de uma xenofobia, nas palavras do psicanalista Vinãr), já presente entre os gregos em relação aos não-gregos (os bárbaros), também é encontrado entre muitos povos ou comunidades e tem sido levado ao extremo e de forma evidente desde os movimentos colonialistas.

O europeu moderno usou do mesmo expediente em relação ao homem do novo mundo, denominando-o de selvagem. E considerando que quem denomina domina, a denominação fica aderida à pele do denominado; assim, está posta a etiqueta que imprime a percepção do julgamento que interessa ao dominador. Viñar vai mais além: "reconhecer e qualificar o outro é um problema difícil e interminável como um labirinto (...) o outro como alguém a subjugar ou a exterminar." (1998, p. 175)

De acordo com Eurídice Figueiredo (1993, p. 15-16), "os clichês que um povo tem de outro povo (ou sobre a população de seu próprio país) são a expressão de um olhar que fragmenta, simplifica e deforma uma realidade muito mais rica e complexa." Marina Yaaguello comunga do mesmo sentimento de Figueiredo: “a função dos estereótipos é justamente o de ocultar a realidade, operando simplificações confortáveis" (1978, p. 57).

Seguindo o fio de Viñar, o outro sempre me coloca "desafios para os quais não tenho uma resposta clara, mas sim hesitações contraditórias" (p. 175). E um caminho da superação do conflito, segundo ele, é

tematizar e gerar narrativas que permitam simbolizar a presença do semelhante e do diferente em duas existências não excludentes, sabendo que a metáfora conciliadora e a metáfora da exclusão sempre rondam por aí e culminam no aparecimento de um entendimento, ou na monstruosidade de um sacrificado e um torturador. (VIÑAR, 1998, p. 175).

Num outro diapasão, a contribuição de Todorov (1982) é exemplar ao explicitar que as possibilidades de encontro com a alteridade dão-se em três dimensões: amar-odiar, conquistar e conhecer. Em conhecendo o outro, eu construo uma imagem de mim, de minha comunidade, de meu grupo, num processo dinâmico de múltiplas faces, que contraria a ideia de identidade fixa, tanto individual quanto nacional. É em Viñar (1998), quem convocamos para abordarmos a noção de identidade nacional:

Comunidade imaginária - artefato ou constructo cultural, produzido por um ato de reflexão: a identidade nacional é, acima de tudo, uma "criação discursiva". Não há um objeto ou referente que a constitua como preexistente ao discurso, mas sim como sendo seu produto. (...) somos o que somos, não por um fatalismo de imanência essencialista, mas somos o que coletivamente podemos construir, na dinâmica de um tecido social em contínua metamorfose e na reformulação contínua de suas expressões jurídico-institucionais. (p.179). 
Finalizando este item, recorremos a Kristeva (1988), que dedicou um de seus estudos ao ser estrangeiro, estando na França como estrangeira. Nas palavras dessa autora,

Em nenhum lugar se é mais estrangeiro do que na França. Sem ter a tolerância dos protestantes anglo-saxões, nem a tendência à despreocupação dos latinos do sul, ou a curiosidade tão excludente quanto assimiladora dos alemães ou dos eslavos, os franceses opõem ao estrangeiro um tecido social compacto e de um orgulho nacional imbatível. (KRISTEVA, 1988, p. 44) ${ }^{3}$

E acrescenta: “(...)em nenhum lugar se é melhor estrangeiro do que na França.”. E continua: “(...) Você é um problema, um desejo positivo ou negativo, jamais neutro.” (KRISTEVA, 1988, p. 45).

Considerando esse breve quadro teórico, passamos à análise das Histórias em Quadrinhos (HQ) Asterix a partir das quais buscamos evidenciar essa relação do eu (gaulês = francês) e do outro (romano = bárbaro).

\section{Análise}

A saga de Asterix se passa no ano 50 a.e.c., durante a expansão do Império Romano. O texto de abertura da HQ “A Cizânia” (1986) diz: Toda Gália foi ocupada pelos romanos... Toda? Não! Uma aldeia povoada por irredutíveis gauleses ainda resiste ao invasor. $\mathbf{E}$ a vida não é nada fácil para as guarnições de legionários romanos nos campos fortificados de BABAORVM, AQUARIVM, LAVDANVM e PETIBONVM. ${ }^{4}$

A estória de "A Cizânia" trata da tentativa dos romanos de semear a discórdia entre os gauleses. Cizânia pode as seguintes acepções: 1. Gramínia nociva aos trigais; erva daninha; joio; Fig. Desavença, discórdia, incompatibilidade.

O personagem escolhido para disseminar a discórdia entre os gauleses, para ser a erva daninha no campo alheio, como único modo de enfraquecê-los, é descrito como não tendo nenhum caráter. Ninguém consegue ficar perto de tal personagem por muito tempo porque ele consegue levantar suspeitas entre as pessoas de tal forma que essas passam a odiarem-se e a se agredirem. Tendo em vista essa característica, Tullius Detritus ${ }^{5}$ (observem o nome da personagem que remete a detrito, escremento) é contratado por subordinados de Júlio César para que se infiltre na aldeia gálica de Asterix e dissemine a maledicência, a cisão, e os enfraqueça.

A astúcia do estrategista romano Tullius Detritus lhe permite iniciar um processo de discórdia. No entanto, como os heróis da HQ são superiores, descobrem a artimanha e revertem a situação. No decorrer da narrativa, algumas passagens

\footnotetext{
${ }^{3}$ No original: Nulle part on n'est plus étranger qu'en France. N'ayant ni la tolérance des protestants anglo-saxons, ni l'insouciance poreuse des Latins du Sud, ni la curiosité rejetante autant qu'assimilatrice des Allemands ou des Slaves, opposent à l'étranger un tissu social compact et d'un orgueil national imbattable. (p.57-8)

(...)nulle part on n'est mieux étranger qu'en France. (p. 58). (ênfase da autora) (...) Vous êtes un problème, un désir: positif ou négatif, jamais neutre. (p. 59).

${ }^{4}$ Os pictogramas dos quadrinhos não estão aqui disponibilizados por barreiras de direitos autorais das imagens.

${ }^{5}$ Os nomes dos romanos são em latim, com terminações como -us ou -ius. Por exemplo: Caius Obtusus e Quebraossus. Em geral, são denominações jocosas. O dos gauleses têm terminações em -ix. Por exemplo: Obelix, Asterix e Ideiafix (nome do cachorro da aldeia) que remetem à raiz "rex" = "rei".
} 
evidenciam de que posição falam os gauleses quando em confronto com os romanos, quais as imagens daí decorrentes, bem como dos romanos ao se referirem ou se dirigirem aos gauleses, e ainda como os romanos são retratados.

\section{Imagem que os romanos têm dos gauleses:}

Enquadramentos 2 e 3: No senado romano, o senador Stradivarius ${ }^{*}$, enfrentando Júlio César, já que ele não consegue invadir e conquistar um grupo de gauleses, diz:

... Existe uma pequena aldeia, lá em cima, na Gália, que desafia nossas forças de ocupação, e recusa a nossa lei. (e aponta para a pequena aldeia gaulesa no enquadramento 1).

Enquadramentos 12 e 13: Num jantar romano no palácio de César: (uma personagem) ...Eles são fortes porque são unidos. Se conseguirmos semear a cizânia, a discórdia na aldeia, eles acabariam se dispersando, e a poção não serviria mais de nada.

(Júlio César) Apesar de os gauleses serem famosos por suas brigas incessantes, os dessa aldeia são unidos até a morte.

A imagem que podemos indicar é a de que os gauleses (IA) são inteligentes, unidos, invencíveis porque têm algo de superior (união) e de mágico (a poção).

\section{Imagem dos romanos na HQ:}

Enquadramento 35 - Romanos brigando durante um jantar, melhor dizendo, socando-se brutalmente, após terem sido apresentados a Tullius Detritus. Mas não é preciso ter um elemento nocivo entre eles, como o estrategista provocador de discórdia, para os romanos serem retratados como brigões e brutos. Em outros enquadramentos os romanos se nocauteiam com frequência. Vamos ao dizeres dos balloons do enquadramento 35: CRÁPULA! BANDIDO!

\section{ARRIVISTA! TRAIDOR!}

As letras estão todas em caixa alta e em negrito, indicando agressividade, brutalidade; o balloom está com fundo verde e seta irregular em forma de raios, indicativos de fala explosiva.

Enquadramentos de $\mathrm{n}^{\circ} 175$ a 184 . O estrategista romano Tullius Detritus está armando seu plano de estabelecimento da discórdia entre os gauleses e leva consigo um legionário chamado Motocontinus. Tullius explica o que vem a ser uma guerra psicológica. Apronta a armadilha e manda Motocontinus atacar Veteranix, o mais velho da tribo, com uma pancada na cabeça, e coloca o minúsculo capacete do legionário (pois, embora seu corpo seja enorme, sua cabeça é pequenina e estreita, indicativo de baixa inteligência) ao lado do velho desacordado, para parecer que os romanos estão tão fortes que até guerreiros pequenos atacam com muita força. Como o legionário realiza uma ação bastante conhecida a ele, que é a luta, o ataque corporal, ele comenta ter gostado muito de ter aprendido o que é uma guerra psicológica: Sabe, gostei muito da guerra psicológica. E sai batendo em outros legionários em enquadramentos à frente, repetindo que era uma guerra psicológica. Ele só cumpriu ordens do estrategista e não entendeu o plano geral. Daí o cômico e daí a imagem de sonso, parvo (IB).

\footnotetext{
* Nome de uma marca famosa de violino. Há uma série de referências irônicas ou cômicas em toda a obra de Goscinny e Uderzo, especialmente em relação a elementos da cultura europeia.
} 
Imagem dos gauleses na $\mathrm{HQ}$ :

Enquadramento 149: Asterix está sendo acusado de ser traidor por acreditarem ter ele passado para o lado dos romanos. Alguns gauleses estão do seu lado, pois acreditam na sua fidelidade; outros, contra ele. E brigam ente si, socandose violentamente: ASTERIX É UM TRAIDOR！NÃO SENHOR！SIM SENHOR! Novamente os balloons estão com fundo verde, indicando alta agressividade.

\section{Síntese das imagens:}

Gauleses: inteligentes, superiores, brigões (IA)

Romanos do alto escalão: articuladores de golpes estratégicos e brutos (IB)

Romanos do exército, os centuriões e os legionários: brutos e burros (IB)

Na outra HQ, "AAsterix e A Surpresa de César", dois jovens personagens gauleses - Falbalá e Tragicomix - são "sequestradas" por um soldado romano que acabara de chegar no acampamento próximo da Armórica (gauleses) e quis mostrar serviço, ainda que advertido para não mexer com os gauleses. Asterix e Obelix partem em busca dos dois jovens. Acabam se alistando no exército romano e, depois de peripécias pela África, chegam à Cidade Eterna (Roma). Para poder livrar Falbalá e Tragicomix dos leões no espetáculo de consagração de César no Coliseu, organizado por Caius Obtusus, os heróis da HQ se inscrevem como gladiadores. Durante a luta com os leões, Asterix e Tragicomix bebem a poção mágica e atiram os animais ferozes nas arquibancadas, provocando pânico e confusão. Obelix, que não precisa beber da poção, pois caiu nela quando criança, esbarra numa coluna de mármore do Coliseu e esse vem abaixo (uma foto atual do Coliseu semi-destruído, em forma de cartão postal, encontra-se estampada nas páginas finais da $\mathrm{HQ}$, numa alusão ao estado atual - de ruína - do Coliseu em Roma e que também aparece nos cartões postais italianos). No final da narrativa, César não tem outra opção a não ser libertar os dois jovens gauleses escravizados pelos seus súditos. Vejamos alguns enquadramentos.

\section{Imagens dos gauleses na HQ}

Enquadramentos 60 a 64 - Asterix e Obelix dirigem-se à cozinha do quartel-general do exército romano, onde se alistaram, para jantar. Obelix, dirigindo-se a Asterix, diz:

- Asterix, você acha que vão servir javali?

- Ah! Obelix, fique sabendo que quanto mais os exércitos são poderosos pior é a comida! Isso deixa os guerreiros de mau humor!

E realmente é isso o que ocorre. Vejamos a sequência discursiva:

(Asterix narrando) Logo vão cuidar de nós: um legionário entra com um caldeirão fumegante. Com uma concha SPLOTCH! - ele enche as nossas gamelas. E logo a mistura faz efeito sobre o nosso humor de guerreiro romano: 
(Obelix) - Pfff! Eu não sabia que o exército romano era tão poderoso assim. Fora de bincadeira, cozinheira, o que é isso?

(Cozinheiro) - A ração do legionário. Trigo, toucinho e queijo. Cozinhamos tudo junto para ganhar tempo.

(Obelix) - E é a mesma coisa todo dia?

(Cozinheiro) - Ah não! Domingo, servimos porções duplas!

(...)

(Asterix narrando) Obelix não aguenta esse atentado àquilo que é mais sagrado para ele: sua gulodice. Então, sem hesitar, vamos conversar com o cuca.

(Asterix e Obelix) - Ei! É você que prepara a comida?

(Cozinheiro) - Por quê?

(Asterix e Obelix) - Porque ela é uma droga!

Final da cena: Obelix deixa o cozinheiro com o olho preto jogado dentro do caldeirão.

Do jogo cômico a respeito da péssima qualidade da comida do exército romano (IB) em relação à excelência do exército emerge a imagem de gauleses como apreciadores da boa comida (IA) e dos romanos como aqueles brutos que comem qualquer mistura (IB). E trata-se de uma mistura clássica para o imaginário da região itálica: trigo (massas), toucinho (gordura) e queijo (a finalização típica da comida regional romana). Em outras palavras: nenhuma sofisticação gastronômica como a da culinária francesa (IA).

\section{Imagens dos romanos na $\mathrm{HQ}$}

Enquadramentos 53 a 58 - Asterix e Obelix chegam ao quartel-general de Condate, à procura de Tragicomix e Falbalá. Vamos às sequências:

(Asterix narrando): Apresento-me com gentileza ao legionário de sentinela. Mesmo assim:

(Legionário) - Não pode passar, gaulês. Se quer se alistar, entre na fila como os outros!

(Asterix) - Desculpe, eu só vim até aqui para conseguir uma informação...

(Legionário) - Entre na fila, gaulês, já disse!

(Asterix comentando): Este militar não tinha a menor civilidade, e eu me vi obrigado a usar minha força de persuasão. Ou seja, o uso da força física!

Deste breve trecho emergem representações que concorrem para a construção da imagem do gaulês (IA) como pessoa civilizada, gentil (pelo menos no início de uma conversação) com um estrangeiro (IB). O confronto que aí ocorre 
entre representantes de etnias em oposição é marcado de modo binário: qualidades positivas para o gaulês e negativas para o romano.

\section{Síntese das imagens}

Gauleses: apreciadores de boa comida (IA) - positivação

Romanos: comem qualquer gororoba (IB) - negativização

Gauleses: educados num primeiro momento (IA)

Romanos: grosseiros sempre (IB)

\section{Palavras finais}

As HQ de Groscinny e Uderzo são materialidades discursivas que constróem uma imagem de gauleses (leia-se franceses), jogando com o tempo (passado e presente), bastante positivada, ao passo que a imagem construída dos romanos, esse outro diferente, é a do bárbaro e incivilizado, portanto negativada. Retomando Viñar (1998), dizemos que a HQ Asterix é uma narrativa construída que materializa e ao mesmo tempo constitui o imaginário francês em relação ao estrangeiro. Pela narrativa de feitos heróicos de um grupo resistente (gauleses), que não se deixa dominar pela força do estrangeiro, uma imagem de comunidade superior é construída e cristalizada na HQ. Veja de denominação positiva -ix dos gauleses: Asterix, Obelix; e-us, ius dos romanos: Caius Obtusus, Motocontinus, Tullius Detritus. Tais denominações são bem indicativas da imagem que é construída e projetada nas HQ de Goscinny e Uderzo. Tal glorificação da supremacia dos gauleses (IA) positivada e da ignomínia ou infâmia dos romanos (IB) negativada se dá no plano da narrativa como forma de engrandecimento da cultura gaulesa (leia-se, por extensão, francesa) reescrevendo eventos da história da conquista romana como sendo verdadeiros, já que os mais ferrenhos opositores do império romano não foram exatamente ou gauleses, como registrado em documentos como De Bello Gallico, de Júlio César, cujo relato é sobre as operações militares sobre seu comando entre os anos 58 a 52 a.e.c. das quais saiu-se vencedor.

Retomando Todorov (1991), das três possibilidades de encontro com a alteridade, as possíveis de serem apontadas no fio discursivo das HQ analisadas são: amar-odiar, já que as emoções mobilizadas de ódio ao outro estão sempre sendo os motivos de litígio entre interesses díspares; e conhecer, como forma possível ou como estratégia de estabelecimento de limites entre o eu e o outro para poder dominar.

\section{Referências}

FIGUEIREDO, E. O olhar do outro: representações sobre brasileiros e franceses. Cadernos de Letras da UFF, n. 7 - Diálogo de culturas - p. 15-24, 1973.

FOUCAULT, M. A Ordem do discurso. São Paulo: Loyola, 1999.

GOSCINNY, R.; UDERZO, A.. Asterix e A surpresa de César. Tradução de Cláudio Varga. São Paulo: Record, abril 1987.

GOSCINNY, R.; UDERZO, A.. A Cizânia. Tradução de Cláudio Varga. São Paulo: Record, vol. 15, maio 1986.

KRISTEVA, J. Étrangers à nous-mêmes. Paris: Fayard, 1988. 
LÉVI-STRAUS, C. Race et histoire. In: Anthropologie structurale deux. Paris: Plon, 1973.

MAFEJE, A.. The Theory and Ethnography of African Social Formations: The Case of the Interlacustrine Kingdoms, London: Codesria, 1991.

MAFEJE, A.. Africanity: A Combative Ontology. CODESRIA Bulletin, vol.1, p.66-71, 2000.

PÊCHEUX, Michel. Análise automática do discurso. In: Gadet, F.; Hak, T. (Orgs.). Por uma análise automática do discurso. Uma introdução à obra de Michel Pêcheux. Campinas: Editora da Unicamp, 1993, p. 61-162.

TODOROV, T. A Conquista da América: a questão do outro. São Paulo: Martins Fontes, 1991.

VIÑAR, M. O reconhecimento do próximo. Notas para pensar o ódio ao estrangeiro. In: KOLTAI, C.(Org.). O

Estrangeiro. São Paulo: Escuta/Fapesp, 1998, p. 173-192. 